\title{
SELECTIVE CATALYTIC REDUCTION OF NITROGEN OXIDE WITH AMMONIA IN A NOVEL REACTOR CALLED "THE FLOATING GAS-SOLID FLUIDIZED BED"
}

\author{
G. J. KWANT \\ Gist-brocades, PO Box 1, 2600 MA Delft, The Netherlands \\ W. PRINS* and W. P. M. VAN SWAAIJ \\ Twente University, PO Box 217, 7500 AE Enschede, The Netherlands
}

(Received May 1994; accepted for publication 10 October 1994)

\begin{abstract}
The floating gas-solid fluidized bed (FGSFB) is a new type of gas-solid contacting device described earlier by Kwant et al. (Fluidization VII, Proc. 7 th Engng Found. Conf. on Fluidization, Brisbane, May, 1992). It is a tapered column provided with several coarse grids, in which catalyst particles are fluidized by a gas at a velocity decreasing with height from a value larger than the single particle terminal falling velocity $U_{1}$ at the bottom to a value still higher than the minimum fluidization velocity at the top.

This paper reports on the results of experiments concerning the application of the FGSFB as a reactor for the removal of $\mathrm{NO}_{\mathbf{x}}$ from flue gas. The selective catalytic reduction of NO with ammonia has been investigated in a column of $2 \mathrm{~m}$ height and cross-sectional area varying from $0.10 \times 0.10 \mathrm{~m}^{2}$ at the bottom to $0.25 \times 0.25 \mathrm{~m}^{2}$ at the top (apex angle: $4.7^{\circ}$ ); $1.7 \mathrm{~mm}$ diameler porous silica spheres containing $\mathrm{V}_{2} \mathrm{O}_{5} / \mathrm{TiO}_{2}$ were used as a catalyst material and fluidized by a simulated flue gas (at $523,573,623$ or $673 \mathrm{~K}$ ) from a natural gas burner. This gas contained approximately $500 \mathrm{vppm}$ NO and was fed at flow rates varying from 200 to $600 \mathrm{~m}^{3} / \mathrm{h}$.

The results have been compared with those obtained in fixed beds operated at the same conditions. Almost the same NO conversion levels were found at equal space velocities; it was therefore concluded that the contacting efficiency corresponds to that in an ideally contacted (high Reynolds numbers) plug flow system. This means that there is no gas bypassing the solids in the FGSFB.

The NO conversion behaviour of the FGSFB reactor was also simulated with a plug flow reactor model using simplified kinetics and an empirical correlation for the axial particle distribution. The S-shaped form of calculated curves, representing the NO conversion degree as a function of the axial position for different values of the reaction rate constant, are characteristic for a FGSFB: the slope increase in the bottom part of the reactor is caused by an increasing conversion rate due to a positive particle concentration gradient in the upwards direction. The decreasing slope beyond the inflection points corresponds of course to the depletion of reactants which becomes dominant upon approaching complete conversion.
\end{abstract}

\section{INTRODUCTION}

The floating gas-solid fluidized bed (FGSFB) has already been introduced in an earlier publication (Kwant et al., 1992). Gas and fluidized spherical particles are contacted in a tapered column in which grid inserts prevent the formation of large heterogeneities and of severe solids-circulation flows. The gas velocity at the entrance of the column is higher than the single particle terminal falling velocity $U_{1}$ (typically 5-10 times $U_{1}$ ), yielding a type of fast fluidized regime at the bottom of the bed with relatively few particles distributed homogeneously over the lowest intergrid compartments. Towards the top of the tapered column the superficial gas velocity decreases gradually, which may result in the bubbling fluidization regime near the top of the bed or, ultimately, in a fixed bed.

The FGSFB can be applied for conversion of gas phase reactants over a solid catalyst. A good example

\footnotetext{
* To whom correspondence should be addressed
}

of such a conversion process is the removal of nitrogen oxides $\left(\mathrm{NO}_{x}\right)$, which are present in flue gas from coal fired boilers used for electric power production, by the selective catalytic reduction (SCR) process. This operation is carried out by mixing flue gas and ammonia after which the mixture is contacted with a vanadia/titania containing catalyst. It was reported (Kwant, 1994) that for a highly selective $\mathrm{V}_{2} \mathrm{O}_{5} / \mathrm{TiO}_{2}$ catalyst on a $\mathrm{SiO}_{2}$ carrier, the conversion process proceeds according to the following overall reaction equation:

$$
4 \mathrm{NO}+4 \mathrm{NH}_{3}+\mathrm{O}_{2} \rightarrow 4 \mathrm{~N}_{2}+6 \mathrm{H}_{2} \mathrm{O} .
$$

This reaction is further referred to as the SCR reaction.

The flue gas from a coal fired boiler has a temperature between 573 and $673 \mathrm{~K}$, and is typically loaded with $10-20 \mathrm{~g} / \mathrm{m}^{3}$ fine fly ash particles ( $<100 \mu \mathrm{m}$ ). Variations (up to $40 \%$ ) in the flue gas flow rate occur quite frequently (roughly four times a day) due to the usual fluctuations in electricity demand. Besides, the installation is turned of and 


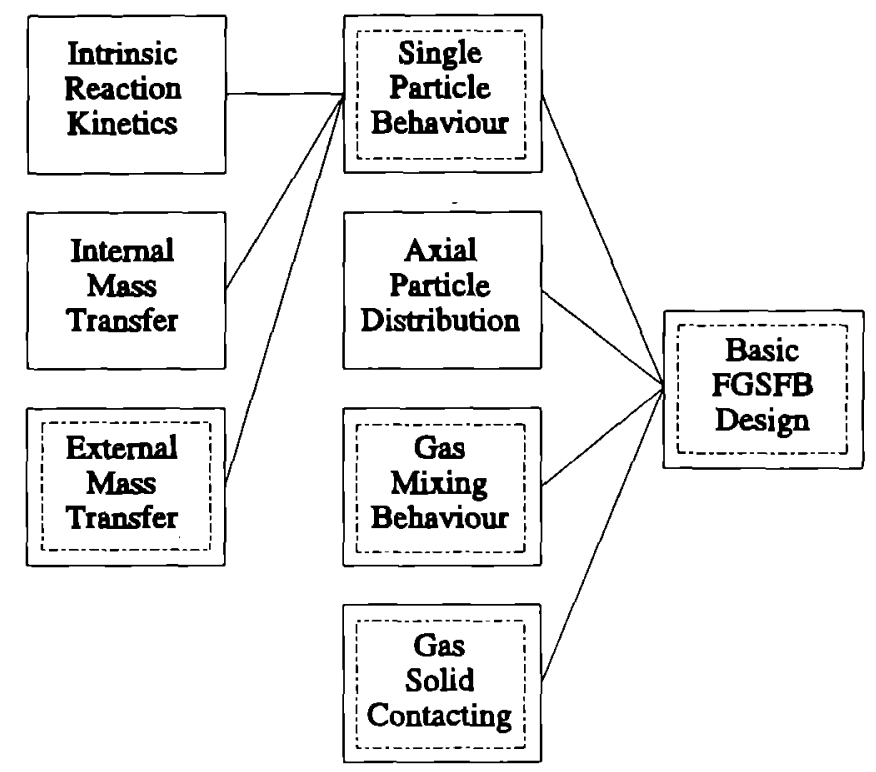

Fig. 1. Schematic illustration of the relation between parameters required to obtain the basic FGSFB design. Dotted squares: parameters not reported before.

restarted many $(+200)$ times a year. Packed or moving bed reactors are not well-suited for the SCR process behind coal fired boilers because the fly ash produced may plug the reactor. Conventional fluidized beds are also not in use for this process, probably because of operational problems caused by the variations in the flue gas flow rate and/or by attrition. Unsatisfactory high ammonia slip via bubbles could also be an operational problem for these reactors. The gas-solid contacting system which is applied instead, the so called "Honey Comb" reactor, suffers from external mass transfer limitation, from non-ideal gas-solid contact and from laborious catalyst replacement. For the latter purpose the process (and power production) should be interrupted for several days. A FGSFB reactor is believed to be a good alternative for these contacting devices since (1) fly ash present in the flue gas cannot stay in the reactor and cause fouling or clogging, (2) the contacting efficiency is expected to be insensitive to gas flow rate changes, (3) catalyst attrition rates are probably small due to the low particle concentration and (4) replacement of the catalyst inventory may be accomplished while operation is continued.

It is not very easy to predict the conversion in a FGSFB reactor a priori because of unknown influences of gas back-mixing, and of gas bypassing the catalyst phase (gas-solid contact). Therefore, a theoretical model is developed and also an experimental study has been carried out. Both the modelling and experimental results are reported later. Figure 1 illustrates which parameters are needed for the reactor model formulation. Phenomena not investigated previously for the FGSFB are indicated by the dotted squares.

The theoretical model starts from the assumption of plug flow for the gas phase, which seems reasonable in view of the large particles and high velocities applied (particle Reynolds numbers are always larger than 100). The possible effect of gas bypassing the solids is accounted for by the introduction of a contactefficiency factor $\zeta$ which will be defined later. Of course the model should also contain an expression for the axial particle distribution; this expression can be derived from pressure drop measurements. First, the typical behaviour of the FGSFB reactor is illustrated by solving the derived conversion model for a first order reaction rate equation. Hereafter, the equations of the previously measured kinetics for the selective catalytic reduction of $\mathrm{NO}_{\mathbf{x}}$ by ammonia (Kwant, 1994) are applied. It is illustrated how pore diffusion limitation and the ammonia inlet concentration affect, theoretically, the performance of this idealized FGSFB SCR reactor.

In the experimental section of this paper, qualitative results on gas back-mixing are reported. These experiments have been carried out by injecting $\mathrm{SO}_{2}$ as tracer gas at several positions in the column while measuring its upstream concentration. Furthermore, results of the $\mathrm{NO}_{x}$ conversion experiments in a pilot scale FGSFB reactor are described. The data obtained are then compared with the experimental $\mathrm{NO}_{\mathbf{r}}$ conversion reported previously (Kwant, 1994) for the case of a fixed bed in which flue gas is ideally contacted (plug flow conditions) with the same catalyst material. The contact efficiency, which is defined as the ratio of the space velocities $\left(S V=\Phi \rho_{\mathrm{p}} / \mathrm{m}\right)$ required to reach in the FGSFB the same conversion level as in an ideally contacted plug flow reactor, is derived from these experiments.

An important practical difficulty with catalytic fluidized bed reactors is the unavoidable loss of active material by attrition. This is also a meaningful problem if the FGSFB is applied for $\mathrm{NO}_{\mathbf{x}}$ reduction 
since (1) the catalyst costs could increase substantially while (2) downstream problems like poisoning of fly ash, e.g. by metal oxides like vanadia, may occur as well. The attrition rate of the catalyst in the FGSFB is believed to depend partly on the extent of the circulation of the solids and therefore on the type of grids applied. Just to estimate the size of the attrition effect in the experimental set-up used for this work, the reduction of the bed mass with time is compared for two types of grid material in a number of separate experiments.

In the rest of this paper $\mathrm{NO}_{x}$ will be replaced by $\mathrm{NO}$, since more than $95 \%$ of nitrogen oxides is present as NO in the flue gas of coal fired boilers. Other nitrogen oxides are therefore assumed to play a negligible role.

\section{PREVIOUS WORK}

The modelling of gas-solid catalytic reactor performance is reported frequently in the literature, especially for plug flow conditions of the gas phase with ideal contact between gas and catalyst particles (i.e. no reduction in conversion of the reactant due to insufficient contact between gas and particles). For the case of nitrogen oxide reduction, the mass balance for NO is given as:

$$
\frac{\mathrm{d}[\mathrm{NO}]_{\mathrm{b}}}{\mathrm{d}(1 / S V)}=-J_{\mathrm{NO}} \frac{6}{d_{\mathrm{p}}} .
$$

This relation states that for plug flow conditions of the gas phase, the change in the bulk concentration of NO with the space velocity $S V$ is dependent on the flux $J_{\text {No }}$ and the specific external surface area $\left(6 / d_{\mathrm{p}}\right)$. The flux is a function of (1) the external mass transfer rates of the reactants and products, (2) the diffusivities inside the particle and (3) the chemical reaction rate. The literature on these parameters will be summarized briefly later.

\section{Gas-to-particle mass transfer}

According to the well-known film model, the external mass transfer rate of gaseous constituents, for example NO, is given by the following flux equation:

$$
J_{\mathrm{NO}}=S h_{\mathrm{NO}} \frac{D_{\mathrm{NO}}}{d_{\mathrm{p}}}\left([\mathrm{NO}]_{\mathrm{b}}-[\mathrm{NO}]_{\mathrm{surr}}\right) .
$$

For the mass transfer coefficient $\left(S h_{\mathrm{NO}}\right)$ a RanzMarshall type of equation is applied which relates the Sherwood number $S h$ to the hydrodynamics and the physical properties of the fluid:

in which:

$$
S h=2+0.6 R e_{\text {efr }}^{1 / 2} S c^{1 / 3}
$$

$$
\operatorname{Re}_{\mathrm{eff}}=\frac{\operatorname{Re}}{\varepsilon}
$$

It should be noted that the porosity $\varepsilon$ in this equation is defined as the average local intergrid porosity in the FGSFB.
Internal mass transfer rate and kinetics

The flux to a spherical particle in which a chemical reaction proceeds, is given by (e.g. Aris, 1965):

$$
J_{\mathrm{NO}}=\frac{d_{\mathrm{p}}}{6} R_{\mathrm{surf}} \eta
$$

in which $\eta$ is the so called catalyst effectiveness factor: this parameter relates the actual flux of a gaseous constituent to the theoretical conversion rate if external surface conditions of the particle prevail inside the entire particle. It has been reported (Aris, 1965) that the exact effectiveness factor for a first order monomolecular reaction can be expressed as:

$$
\eta=\frac{1}{\varphi}\left(\frac{1}{\tanh (3 \varphi)}-\frac{1}{3 \varphi}\right)
$$

For NO in the SCR reaction system the reaction modulus $\varphi$, introduced in eq. (6), was derived earlier as (Kwant, 1994):

$$
\frac{1}{\varphi} \frac{\left(6 / d_{\mathrm{p}}\right) D_{\mathrm{NO} . \mathrm{eff}}}{R_{\mathrm{surf}}} \sqrt{\int_{[\mathrm{NO}]_{\mathrm{m}}}^{\mathrm{[NO}]_{\mathrm{sur}}} R \delta[\mathrm{NO}]}
$$

while the effective diflusivity $D_{\mathrm{No} \text { efr }}$ in eq. (7) is calculated from:

$$
\frac{1}{D_{\mathrm{NO}, \mathrm{eIf}}}=\frac{\gamma}{\varepsilon_{\mathrm{p}}}\left(\frac{1}{D_{\mathrm{NO}, \mathrm{mol}}}+\frac{1}{D_{\mathrm{NO}, \mathrm{kn}}}\right) .
$$

The value of $[\mathrm{NO}]_{m}$ in eq. (7) is defined as the nitrogen oxide concentration which would occur in the centre of the particle if an infinitely fast reaction proceeded. Furthermore, it was shown previously that $\left[\mathrm{NH}_{3}\right]$, the ammonia concentration inside a porous catalyst particle in which the SCR reaction proceeds, can be expressed in terms of the concentration values $\left[\mathrm{NH}_{3}\right]_{b_{2}, 0},[\mathrm{NO}]_{b, 0},[\mathrm{NO}]_{b},[\mathrm{NO}]_{\text {surf }},[\mathrm{NO}]$ and mass transport parameters like $S h$ and the effective diffusivities (Kwant, 1994). The gas phase concentrations of the various reactants in a multi-component system where only one reaction proceeds can be related to each other by equating their molar fluxes to (external mass transfer equations) and into (Fick's law of diffusion) the catalyst particle. As a consequence, the rate equations (9)-(10) and the reaction modulus can be rewritten in terms independent of the local ammonia concentration inside the particle. It is also for this relation between the local ammonia and NO concentration that $[\mathrm{NO}]_{\mathrm{m}}$ is not necessarily equal to 0 .

A literature review on the kinetics of the catalytic reactions for NO reduction by ammonia, which is the current reaction system, has been presented by Bosch and Janssen (1988). For the presently proposed model a reaction rate equation which has been derived experimentally in another study will be used (Kwant, 1994).

$$
R=k_{+2} K_{1} \frac{[\mathrm{NO}]\left[\mathrm{NH}_{3}\right]}{1+K_{2}[\mathrm{NO}]} \theta^{2}
$$


Table 1. Experimental values of kinetic constants $K_{i}$ for three operating temperatures (values derived in Kwant, 1994)

\begin{tabular}{lccc}
\hline Constants & \multicolumn{3}{c}{ Temperature (K) } \\
\cline { 2 - 4 } & 573 & 623 & 673 \\
\hline$k_{+2}(1 / \mathrm{s})$ & 170 & 358 & 407 \\
$K_{1}\left(\mathrm{~m}^{3} / \mathrm{mol}\right)$ & 582 & 268 & 232 \\
$K_{2}\left(\mathrm{~m}^{3} / \mathrm{mol}\right)$ & 182 & 194 & 204 \\
$K_{3}$ & 0.99 & 1.13 & 1.21 \\
\hline
\end{tabular}

in which:

$$
\begin{aligned}
\theta= & -\frac{1+K_{3}\left(1+K_{2}[\mathrm{NO}]\right)}{4 K_{1}} \frac{\left[\mathrm{NH}_{3}\right]}{\left[\left(\frac{1+K_{3}}{4 K_{1}} \frac{\left(1+K_{2}[\mathrm{NO}]\right.}{\left[\mathrm{NH}_{3}\right]}\right)+\frac{1+K_{2}[\mathrm{NO}]}{K_{1}\left[\mathrm{NH}_{3}\right]}\right.} \\
& +\sqrt{\left(\frac{1}{1}\right)}
\end{aligned}
$$

It is based on a (Eley Rideal type of) mechanistic surface conversion model and explains orders in NO and $\mathrm{NH}_{3}$ (ranging from zero to one; see Bosch and Janssen, 1988) reported before. The constants appearing in the equation (see Table l) have been quantified by fitting the results of kinetic measurements to the proposed kinetic model. A remarkable result is the low activation energy observed (approx. $25 \mathrm{~kJ} / \mathrm{mol}$ ); the effect of temperature on the rate of the SCR reaction is included in the values of the constants listed in Table 1.

\section{Axial particle distribution}

With the above equations (1)-(10) the conversion of NO in a plug flow, ideally contacted, SCR system can be calculated as a function of the space velocity. This $S V$ can in turn be related to the required volume of a FGSFB reactor if, also, the axial particle distribution in the FGSFB is known. The local particle concentration in the FGSFB is determined by the particle properties, column geometry and operating conditions according to the following relation (see Kwant, 1994):

$$
\frac{U}{U_{\mathrm{l}}}=\frac{\varepsilon}{\sqrt{1+23.3(1-\varepsilon)}} \quad\left(U_{\mathrm{mr}} \leq U \leq U_{\mathrm{l}}\right) .
$$

This equation can be derived by measuring the pressure drop as a function of the height in the reactor. One should note that the superficial gas velocity in a tapered column with a round cross-section is dependent on the axial position (Kwant, 1994):

$$
U=\frac{\Phi_{\mathrm{v}}}{\pi / 4\left(D_{0}+\tan (\alpha) H\right)^{2}} .
$$

\section{Gas mixing and bypassing}

Large particle [Geldart Class D (Geldart, 1973)] systems, fluidized at a relatively low gas velocity are generally characterized by the so called slow bubble regime: the gas velocity in the voids is nearly the same as in the dense suspension phase. At higher velocities spout formation, turbulent or fast fluidization may occur. As a consequence, in each of these cases the effect of channelling should be incorporated in a reactor model. Conveniently, this can be carried out by introducing the contact efficiency, $\zeta$, defined in eq. (16) as the ratio of the space velocities in an ideally contacted plug flow reactor and a fluidized bed to reach the same conversion at the same conditions. Equation (1) therefore reads:

$$
\frac{\mathrm{d}[\mathrm{NO}]_{\mathrm{b}}}{\mathrm{d}\left(\zeta / S V_{\mathrm{PF}}\right)}=-J_{\mathrm{NO}} \frac{6}{d_{\mathrm{p}}}
$$

Recently, a review of fluidized bed reactor models was presented by Kunii and Levenspiel (1991). According to this work, gas nuidized bed reactors of Geldart Class D particles (Geldart, 1973) are best described by a plug flow model with temporary short cuts (slugs). Such a model formulation has been illustrated in Figs 2(a) and 2(b). For the current purpose, modelling of the conversion rate in a large particle fluidized bed is fully equivalent to the well-known single phase plug flow model [Fig. 2(c)]. It is reported (Kunii and Levenspiel, 1991) that the contacting efficiency of gas and catalyst particles is nearly 1.

A second model in the work of Kunii and Levenspiel (1991) accounts for the conversion in the lean free board region. It is based on both the distribution of particles in the free board and the local contacting efficiency. It was reported (Kunii and Levenspiel, 1991) that the particle concentration decays exponentially with height while the contacting efficiency increases (also exponentially) to unity. This finding would hold for all types of particles. In the FGSFB also many of these free-board-alike zones can be recognized, e.g. at the bottom of the bed and below each grid in the heterogeneous fluidized part. Therefore, the contacting efficiency in the FGSFB reactor can be different from unity.

\section{MODEL FOR THE FGSFR REACTOR}

The FGSFB reactor model developed hereafter is a one-dimensional plug flow model with the vertical axis being the main direction. It starts with a steady-state mass balance for a reagent, over an infinite thin, horizontal slab of the column with a volume $\mathrm{d} V(=A \mathrm{~d} H)$.

The conversion of a gaseous constituent in the flowing gas is dependent on the amount of solid material available, the catalytic activity of the active substance upon the surface of the solid material, the concentration level(s) of reactant(s), the external mass transfer rate of the reactant(s) and product(s) to the particles geometric surface area and the diffusivity inside the particle of both reactants and products. The local mass balance for $\mathrm{NO}$ as model reagent, now reads:

$$
\Phi_{v} \mathrm{~d}[\mathrm{NO}]_{b}=-J \mathrm{~d} A_{p}=-J \frac{6}{d_{p}} \mathrm{~d} V_{p}
$$




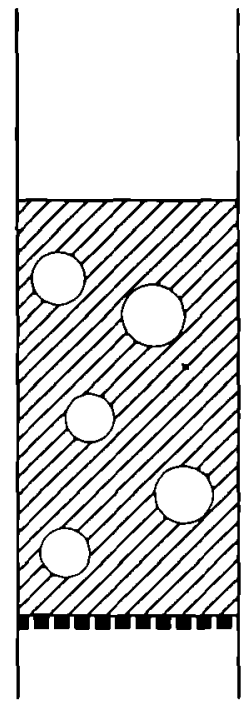

(a)

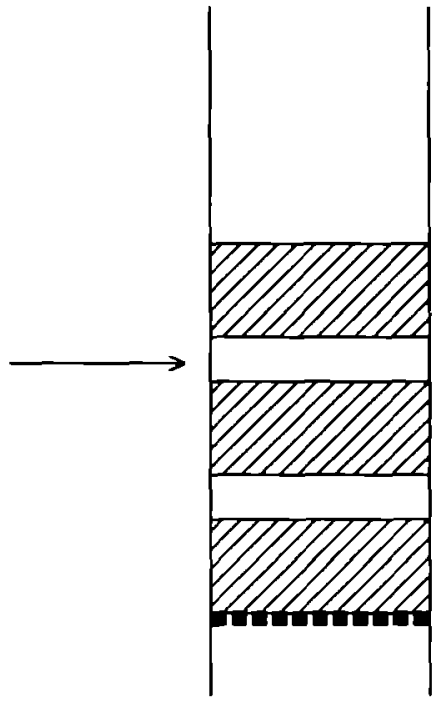

(b)

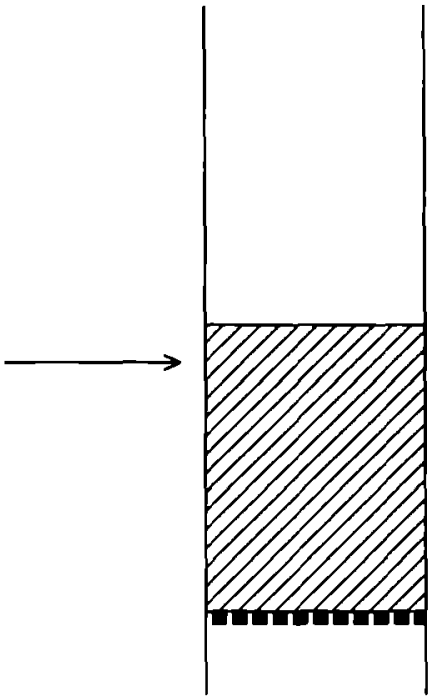

(c)

Fig. 2. Illustration of simplification procedure for modelling of the conversion in a bubbling fluidized bed of large particles: (a) bubbling bed; (b) "sluggish" bed; (c) "fixed" bed.

in which $\mathrm{d} A_{\mathrm{p}}$ denotes the amount of geometrical particle surface area in the control volume and $\mathrm{d} V_{\mathrm{p}}$ the volume of these particles.

To make the model equation independent of the reactor geometry, it is convenient to introduce the space velocity so that it follows that:

$$
\Phi_{\mathrm{v}} \frac{\mathrm{d}[\mathrm{NO}]_{\mathrm{b}}}{\mathrm{d} V_{\mathrm{p}}}=\frac{\mathrm{d}[\mathrm{NO}]_{\mathrm{b}}}{\mathrm{d}\left(V_{\mathrm{p}} / \Phi_{\mathrm{v}}\right)}=\frac{\mathrm{d}[\mathrm{NO}]_{\mathrm{b}}}{\mathrm{d}(1 / S V)}=-J \frac{6}{d_{\mathrm{p}}}
$$

\section{Single particle behaviour}

In the following it will be assumed that NO and ammonia are the reagents converted in the FGSFB reactor. The reader may note that the analysis is also applicable to other systems by using the proper kinetic relations and mass balances.

Kinetics and internal mass transfer rate. Only one (multi-molecular) reaction is assumed to proceed for the current model system: $\mathrm{NO}_{x}$ removal by the SCR reaction. The intrinsic reaction kinetics are provided in eqs (9) and (10) with the constants quantified in Table 1. These relations are incorporated in the concept of the generalized reaction modulus which is applied for calculation of the catalyst effectiveness factor [eqs (6)-(8)].

External mass transfer rate. Equations (2)-(4) are applied to calculate the external mass transfer rate to or from a particle in the FGSFB. The reader should note that eq. (3) cannot be applied for the prediction of the mass transfer coefficient in gas fluidized beds at small Reynolds number $\left(R e_{\text {err }}<10\right)$ (Schlünder, 1977; Palchonok et al., 1992). However, the FGSFB contains large particles; consequently the $R e$ number is quite high $\left(50<R e_{\mathrm{m} r, \min } \leq R e<R e_{1, \max } \leq 1400\right.$ ) and eq. (3) is therefore assumed to be applicable.
Total flux to particles. Both eq. (2) and eq. (5) express the flux to the particles; these still contain the, yet unknown, surface concentration $[\mathrm{NO}]_{\text {surf }}$. The exact value of $[\mathrm{NO}]_{\text {surr }}$ can be derived by iteration. Equations (2) and (5) should eventually yield the same flux for a single value of $[\mathrm{NO}]_{\text {gurf }}$. Substitution of this concentration value in either eq. (2) or eq. (5) yields the total flux into the particle.

\section{Contact efficiency}

In gas-solid fluidized beds the conversion can be smaller than for the same amount of catalyst material contacted in a plug flow contactor (Kunii and Levenspiel, 1991). This is assumed to be caused by gas bypassing the solids suspension phase through bubbles. To account for this effect in the reactor model, the contacting efficiency is defined here as the ratio of the space velocities required to obtain equal conversion levels in a bed under plug fow conditions and the FGSFB respectively:

$$
\zeta=\frac{S V_{\mathrm{PF}}}{S V_{\mathrm{FGSFB}}}=\frac{S V_{\mathrm{PB}}}{S V_{\mathrm{FGSFB}}} .
$$

The space velocity $S V$ is defined as the ratio of the gas flow rate under actual conditions and the applied catalyst volume $\left.\left(S V=\Phi_{\mathrm{v}} / \mathrm{m} / \rho_{\mathrm{p}}\right)\right)$. To account for gas bypassing in the reactor model the plug flow space velocity is divided by the contacting efficiency and this "modified" space velocity is used for conversion calculations. In this way it is possible to derive the required space velocity to reach a certain conversion level in a FGSFB from measurements in an ideally contacted plug flow contactor if the contacting efficiency of the FGSFB is known. 


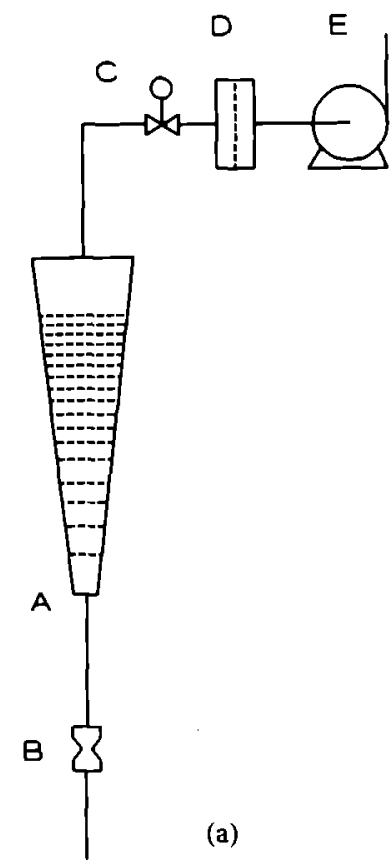

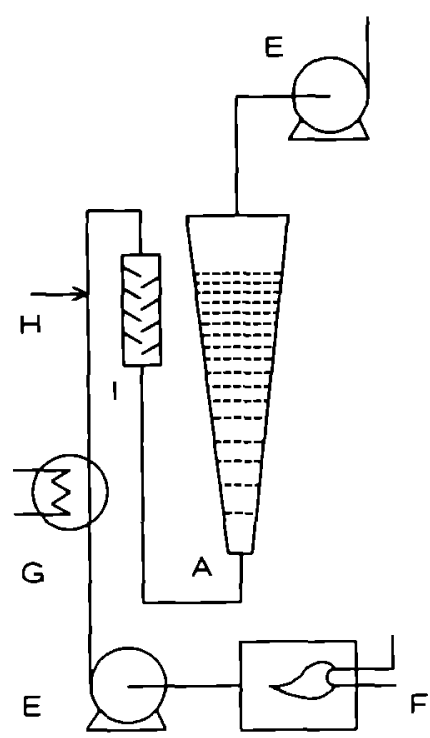

(b)

Fig. 3. Set-ups applied for (a) gas back-mixing (squared tapered column) and (b) for conversion experiments (high temperature tapered column).

Combination of the equations: the reactor model

By now, all relations have been given which are needed to model the FGSFB reactor [eqs (2)-(13), eq. (16)]. However, these cannot be solved analytically because of the dependency of the superficial gas velocity $U$ on the axial position in the column. Values like the Sherwood number and the local porosity can be expressed in the axial coordinate $H$ while the reaction kinetics [eqs (9) and (10)] are also expressed in local concentrations. The surface concentration is obtained by solving eqs (2) and (5) and the result is applied to obtain the flux of NO to the catalyst particle. Equation (13) is subsequently integrated (contact efficiency derived from experiments) and the solutions (axial concentration profiles) are presented and examined in a later section of this paper.

\section{EXPERIMENTAL}

Three types of experiments have been performed, viz. to obtain information on (1) the degree of gas back-mixing (plug flow behaviour), (2) the conversion and the contacting efficiency and (3) the catalyst attrition rate.

\section{Gas back-mixing experiments}

The objective of these experiments was to indicate whether or not gas back-mixing is severe under various conditions and to check if it is correct to assume plug flow behaviour of the gas in the FGSFB reactor. A squared tapered column [Fig. 3(a)] of transparent acrylate has been applied at ambient conditions for gas dispersion experiments in a FGSFB (Kwant, 1994). This column is $2 \mathrm{~m}$ tall with an entrance edge of $0.1 \mathrm{~m}$ and an apex angle of $4.7^{\circ}$ while the volume between two succeeding grids was kept constant $\left(0.0025 \mathrm{~m}^{3}\right)$. Ambient air was applied as fluidizing agent at flow rates varying from $200 \mathrm{~m}^{3} / \mathrm{h}$ to $600 \mathrm{~m}^{3} / \mathrm{h}$.

To start an experiment the column was filled with a weighed amount of $0.0030 \mathrm{~m}$ silica spheres while an air flow rate was applied sufficient to keep all particles suspended in the column. Afterwards, the air flow rate was adjusted to a desired value. Tracer gas $\left(\mathrm{SO}_{2}\right)$ was subsequently injected into the fluidized bed at $0.01-0.03 \mathrm{~m}$ above a certain grid and its concentration has been measured at $\pm 0.01 \mathrm{~m}$ below that grid. Several positions of injection and detection were applied, in corners as well as in the centre of the column.

\section{Conversion experiments/contact efficiency}

These experiments were carried out to obtain information on the conversion rate in a FGSFB reactor and for comparison with data derived from experiments using an ideally contacted plug flow reactor. A $3 \mathrm{~m}$ tall high-temperature column [Kwant (1994), see Fig. 3(b) in this paper] made of stainless steel and provided with (stainless steel) grids of $1 \mathrm{~mm}$ rods (mesh $10 \mathrm{~mm}$ ), was applied. Synthetic flue gas containing 0-500 vppm NO, $15 \%$ water, $8 \% \mathrm{CO}_{2}$ and $3 \%$ oxygen and with a temperature of $523-673 \mathrm{~K}$ was produced by a natural gas burner $\left[ \pm 177 \mathrm{~m}^{3} / \mathrm{h}\right.$ (STP, dry)]. Ammonia was intimately mixed with the flue gas to obtain a concentration in the range $0-500 \mathrm{vppm}$. Spherical particles of $0.0017 \mathrm{~m}$ diameter containing vanadia/titania on silica (generously provided by Koninklijke Shell Laboratorium Amsterdam) were used as catalyst (Kwant, 1994). During an experiment 
ammonia analysis was carried out continuously by applying a titration method; $[\mathrm{NO}]_{b}$ was measured by a standard chemiluminescence technique. The concentration of nitrous oxide $\left(\mathrm{N}_{2} \mathrm{O}\right)$ at the reactor inlet and outlet was always less than 10 vppm (gas chromatography)

Conversion experiments were started by igniting the burner and heating the reactor to the desired operating temperature. A certain mass of catalyst (between 0 and $8 \mathrm{~kg}$ ) was subsequently added to the column and allowed to reach the adjusted operating temperature. Finally, when the isothermal condition prevailed, $[\mathrm{NO}]_{b}$ and $\left[\mathrm{NH}_{3}\right]_{b}$ could be measured at the reactor inlet and outlet.

\section{Attrition rate}

One important problem of fluidized bed reactors is the loss of catalyst material by attrition. For a first quantification of the attrition rate in the FGSFB reactor, experiments were carried out using two different types of grid material. The influence of the type of grid on the behaviour of the FGSFB has been visually observed at ambient conditions [Fig. 3(a)]. Also, the effect on the attrition rate has been investigated at high temperature [Fig. 3(b)]. The original type of grid material consisted of woven $0.001 \mathrm{~m}$ diameter rods with a mesh of $0.010 \mathrm{~m}$. A second type was obtained by simply adding a slightly bent finer grid (mesh $0.005 \mathrm{~m}$ ) on top of each of the former grids. This composite grid is now denoted as a "duo grid" while the original one will be referred to as the "single grid". Both grids were first applied at ambient conditions in the squared tapered column [Fig. 3(a)] and subsequently in the high temperature tapered column [Fig. 3(b)]. The attrition rate for each insert was determined in the high temperature column only, by measuring the difference in bed weight before and after operation of the FGSFB reactor $(T=623 \mathrm{~K})$ during $\pm 200 \mathrm{~h}$ and starting with $8 \mathrm{~kg}$ of $0.0017 \mathrm{~m}$ diameter catalyst material.

\section{RESULTS OF THE EXPERIMENTS}

In the following the results of the various experiments which have been carried out will be reported.

\section{Gas back-mixing}

The $\mathrm{SO}_{2}$ dispersion experiments were carried out to reveal whether or not gas back-mixing occurred. It was found that the gas, injected at several radial positions just above a grid, could not be detected below it. This is an important result because it supports the assumption of plug flow in the vertical direction: back-mixing of gas is absent.

\section{Conversion experiments}

In all these experiments the $\mathrm{NO}$ and ammonia concentrations were measured at the reactor inlet and outlet after which the conversion of both components was calculated. Under the conditions applied a high selectivity towards the SCR reaction was observed, which is in accordance with previous findings (Kwant,
1994): no production of $\mathrm{N}_{2} \mathrm{O}$ was found while the amount of NO and ammonia converted were the same and therefore oxidation of ammonia by oxygen only is excluded.

Typical profiles, obtained by plotting the conversion of NO against the space velocity, are presented in Fig. 4(a) for the four operating temperatures applied. For the data points in this diagram, an increasing $S V$ was obtained by decreasing the bed mass only. Above $573 \mathrm{~K}$, little effect of the operating temperature was observed which is in accordance with the previous results obtained on the reaction kinetics (Kwant, 1994). This behaviour was shown to be related to the properties of the active material and not to hydrodynamic effects such as external mass transfer limitation (Kwant, 1994). In Fig. 4(b) some NO conversion data have been plotted against the inlet ratio $\left[\mathrm{NH}_{3}\right]_{0} /[\mathrm{NO}]_{0}$ value. The trend in the result is the same as the one often reported in literature (e.g. Bosch and Janssen, 1988) and also found previously in a packed bed of this catalyst (Kwant, 1994). The reader should note that NO conversion data up to a $\left[\mathrm{NH}_{3}\right]_{0} /[\mathrm{NO}]_{0}$ of 0.6 also illustrate the high catalyst selectivity: the observed NO conversion corresponds to complete ammonia consumption.

The duo grids were expected to suppress the formation of heterogeneities more effectively than the single grid material. Therefore a number of conversion experiments have been carried out in which the type of grid was different (single or duo grid), while all other conditions $\left(T=623 \mathrm{~K},[\mathrm{NO}]_{0}=\left[\mathrm{NH}_{3}\right]_{0}=\right.$ 500 vppm) were kept the same. Figure 5 shows the result of this comparison in a plot of the NO conversion degree against the applied space velocity. No difference in performance is observed which might be an indication that the effect of the grids on the contacting efficiency is insignificant.

\section{NO conversion at $\left[\mathrm{NH}_{3}\right]_{0} /[\mathrm{NO}]_{0}=0.8$}

A catalytic reactor applied for $\mathrm{NO}$ reduction generally operates at $\left[\mathrm{NH}_{3}\right]_{0} /\left[\mathrm{NO}_{0}=0.8\right.$ and at least $99 \%$ ammonia conversion (e.g. Bosch and Janssen, 1988). The space velocity to reach this value is, therefore, derived by performing experiments at decreasing space velocity. The ammonia conversion results obtained are plotted in Fig. 6. It is derived by extrapolation that the required ammonia conversion level was achievable in the FGSFB at a space velocity of approximately $12.61 / \mathrm{s}(4.8 \mathrm{1} / \mathrm{s}$ (STP, dry)) and this value is almost independent of the operating temperature. The literature (Bosch and Janssen, 1988) suggests a value of $0.81 / \mathrm{s}$ (STP, dry) in conventional SCR systems. This would imply that the currently proposed FGSFB reactor requires a \pm 6 times smaller volume of catalyst for flue gas denoxing than applied in the usual Honey Comb reactor.

\section{Visual observations with duo grid}

It has been observed previously (Kwant, 1994) that in the centre of a FGSFB at ambient conditions a meandering "plume" occurs. During an experiment 


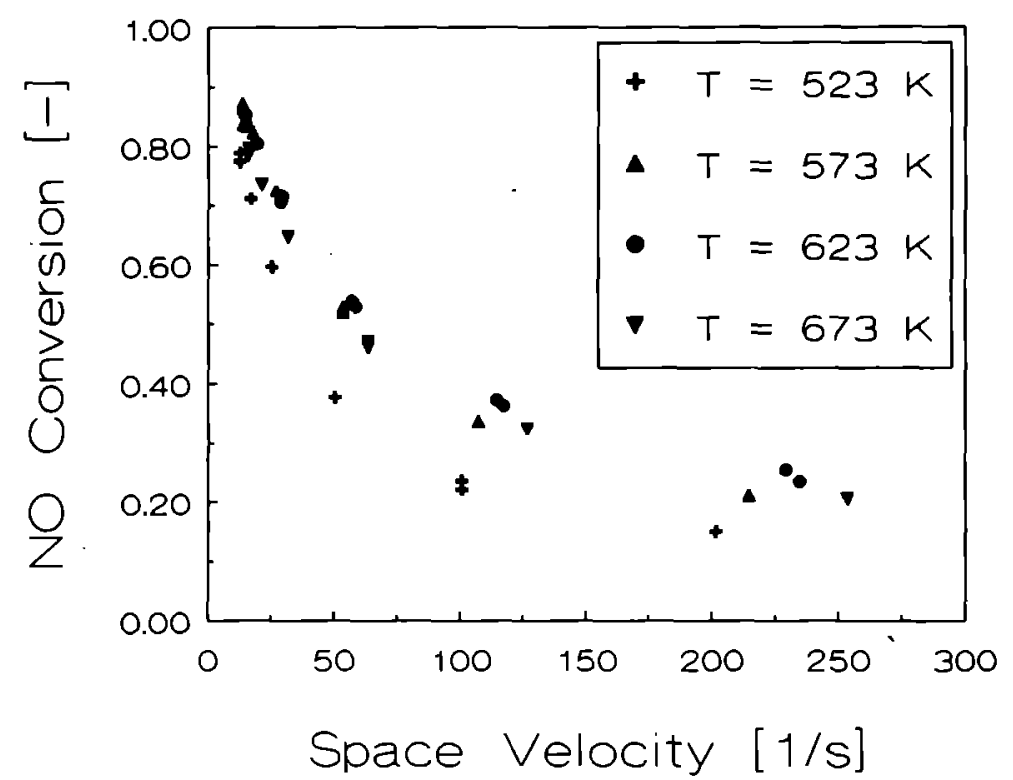

(a)

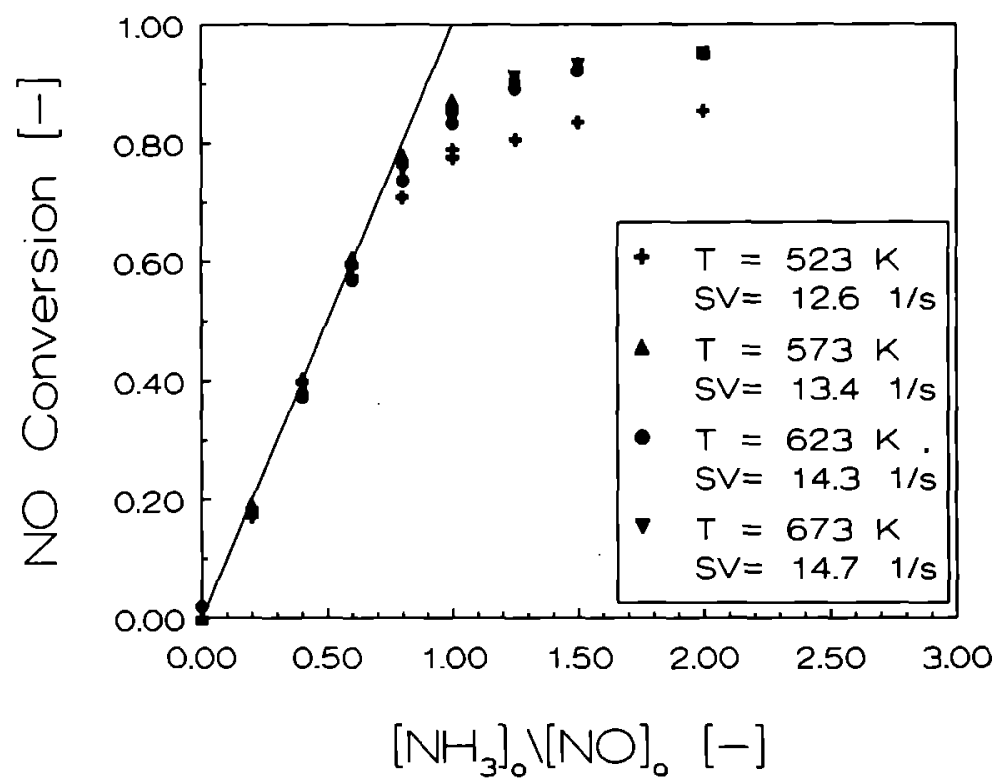

(b)

Fig. 4. Measured NO conversion against (a) the space velocity $\left(\left[\mathrm{NH}_{3}\right]_{0}=500 \mathrm{vppm}\right)$ and (b) the $\left[\mathrm{NH}_{3}\right]_{0} /[\mathrm{NO}]_{0}$ ratio. Data are presented for four operating temperatures: [NO $]_{0}=500 \mathrm{vppm}$, $d_{\mathrm{p}}=0.0017 \mathrm{~m}, \rho_{\mathrm{p}}=925 \mathrm{~kg} / \mathrm{m}^{3}$.

with the duo grid material in the squared tapered column [the same one as sketched in Fig. 3(a)] it was observed that this "plume" did not change or diminish appreciably compared to the single grids. Particle recirculation rates, however, seemed to be less than with the single grid material but this was not quantified any further.

\section{Particle attrition rate}

For each of the two types of grid material described above, experiments lasting $200 \mathrm{~h}$ have been carried out in the high temperature set-up [Fig. $3(\mathrm{~b})]$ with the two types of grid material described above and the SCR catalyst particles. These investigations were meant to study the effect of the type of grid material on the particle attrition rate. It has been found that the use of the original single grids yielded a loss of $0.104 \mathrm{~kg}$ in a bed of $8 \mathrm{~kg}$ catalyst material after $204 \mathrm{~h}$ of operation. However, by application of the duo grids a loss of only $0.004 \mathrm{~kg}$ was found with a bed inventory of $8 \mathrm{~kg}$ after $190 \mathrm{~h}$ of operation. The latter value was considered to be in the range of the error in measurement, but the results clearly indicate the important effect of the grids on the attrition rate. 


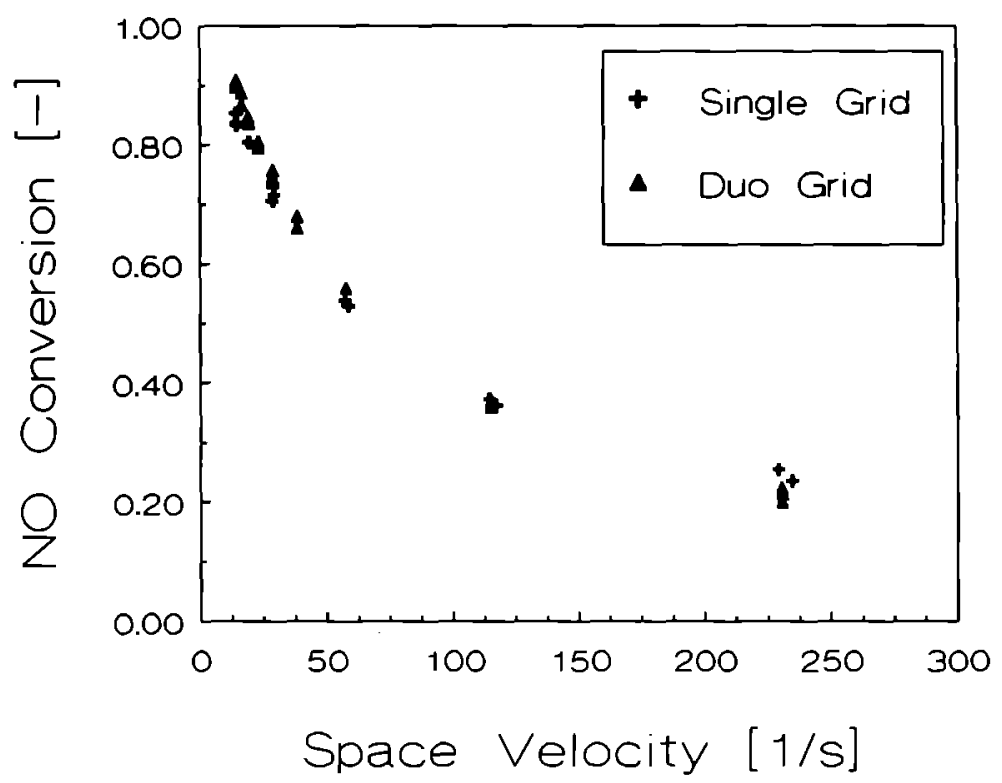

Fig. 5. Experimental NO conversion against the SV $\left(T=623 \mathrm{~K},\left[\mathrm{NH}_{3}\right]_{0}=[\mathrm{NO}]_{0}=500 \mathrm{vppm}\right.$, $d_{\mathrm{p}}=0.0017 \mathrm{~m}, \rho_{\mathrm{p}}=925 \mathrm{~kg} / \mathrm{m}^{3}$ ) for both the single grid and the duo grid type.

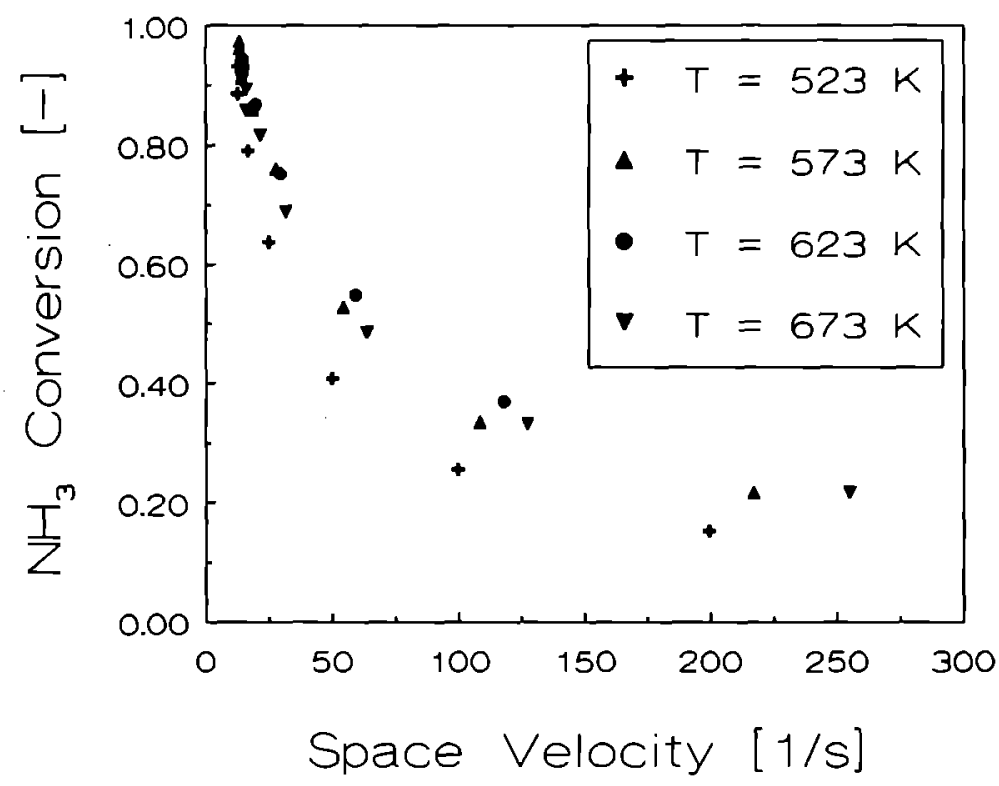

Fig. 6. Measured ammonia conversion against the $\mathrm{SV}$ for four temperatures. Conditions: $\left[\mathrm{NH}_{3}\right]_{0} /\left[\mathrm{NO}_{0}=\right.$ $0.8,[\mathrm{NO}]_{0}=500 \mathrm{vpm}, d_{\mathrm{p}}=0.0017 \mathrm{~m}, \rho_{\mathrm{p}}=925 \mathrm{~kg} / \mathrm{m}^{3}$.

Apparently, the duogrid construction reduces the particle velocity fluctuations and, consequently, the extent of impact-attrition quite effectively. The pressure drop increased only slightly $( \pm 5 \%)$ if a FGSFB was equipped with duo grids instead of single grid material.

\section{RESUlts of model Calculations}

The theoretical model, described in the first part of this work, is applied to illustrate the variation of the concentration with axial position in a plug flow catalytic FGSFB reactor in which a first order, monomolecular reaction proceeds on the geometrical surface of a non-porous catalyst particle. Subsequently, this model is used for porous catalyst particles to illustrate the effect of different particle diameters and of $\left[\mathrm{NH}_{3}\right]_{0} /[\mathrm{NO}]_{0}$ on the local conversion and on the catalyst effectiveness factor. The kinetic relations employed in the latter case are those derived elsewhere (Kwant, 1994) for the SCR reaction [eqs (9) and (10) and the constants in Table 1].

Conversions of NO, obtained from experiments in the FGSFB, are compared to the fixed bed data presented previously (Kwant, 1994) by which the contacting efficiency value needed for the model can be quantified. The latter conversion values are derived from experiments in a plug flow, ideally contacted, 


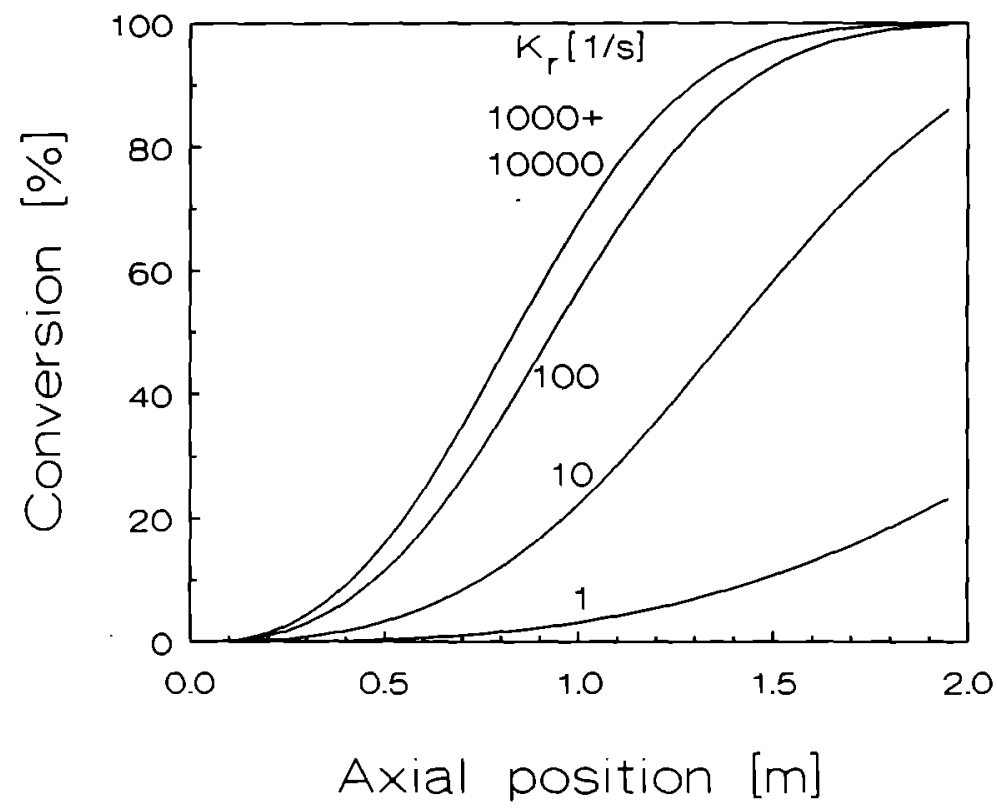

(a)

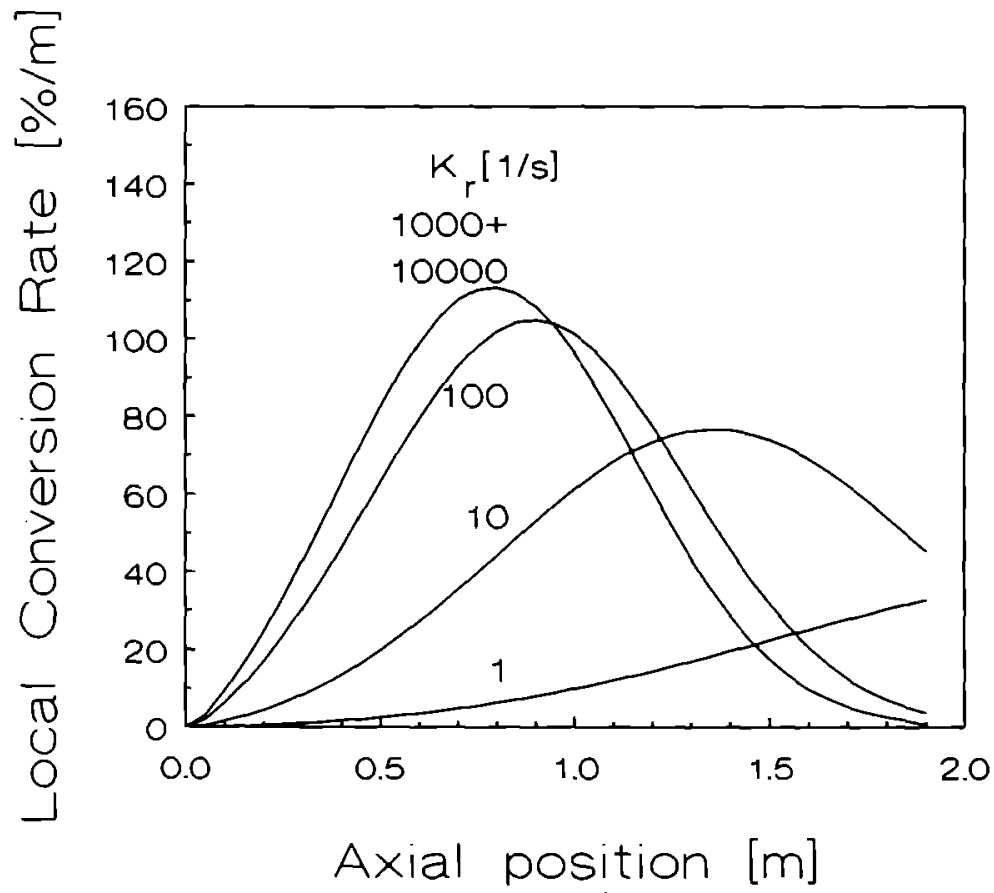

Fig. 7. Calculated conversion (a) and the conversion rate $[\% / \mathrm{m}]$ (b) for a first order reaction against axial position in the FGSFB. Shown are lines for different values of the reaction rate constant $k_{r}$. Non-porous particles, $d_{\mathrm{p}}=0.0017 \mathrm{~m}, \rho_{\mathrm{p}}=925 \mathrm{~kg} / \mathrm{m}^{3}$, flow rate $0.1 \mathrm{~m}^{3} / \mathrm{s}$, apex angle $4.7^{\circ}$, diameter at reactor entrance $0.1 \mathrm{~m}, k_{\mathrm{i}} 6 / d_{\mathrm{p}}=0.0011 / \mathrm{s}$.

packed bed. At the end of this part, the attribution rate using the duo grid and the single grid respectively, is calculated.

\section{Model evaluation}

The reactor model eqs (2)-(5) and eqs (11)-(13) has been applied to compute the conversion profile of an arbitrary first order, monomolecular reaction $\left(R=k_{\mathrm{r}} C\right)$ in an ideally contacted FGSFB reactor containing non-porous catalyst particles. This is done to illustrate a specific feature of the FGSFB as a reactor, viz. that the conversion rate has a maximum value. In Fig. 7 the results of the calculations are plotted against the axial position in the FGSFB reactor for the system given in the legend. Different lines are shown to represent the effect of a variation in the first order reaction rate constant. Clearly, the conversion increases up to 1 [Fig. 7(a)], which is to 


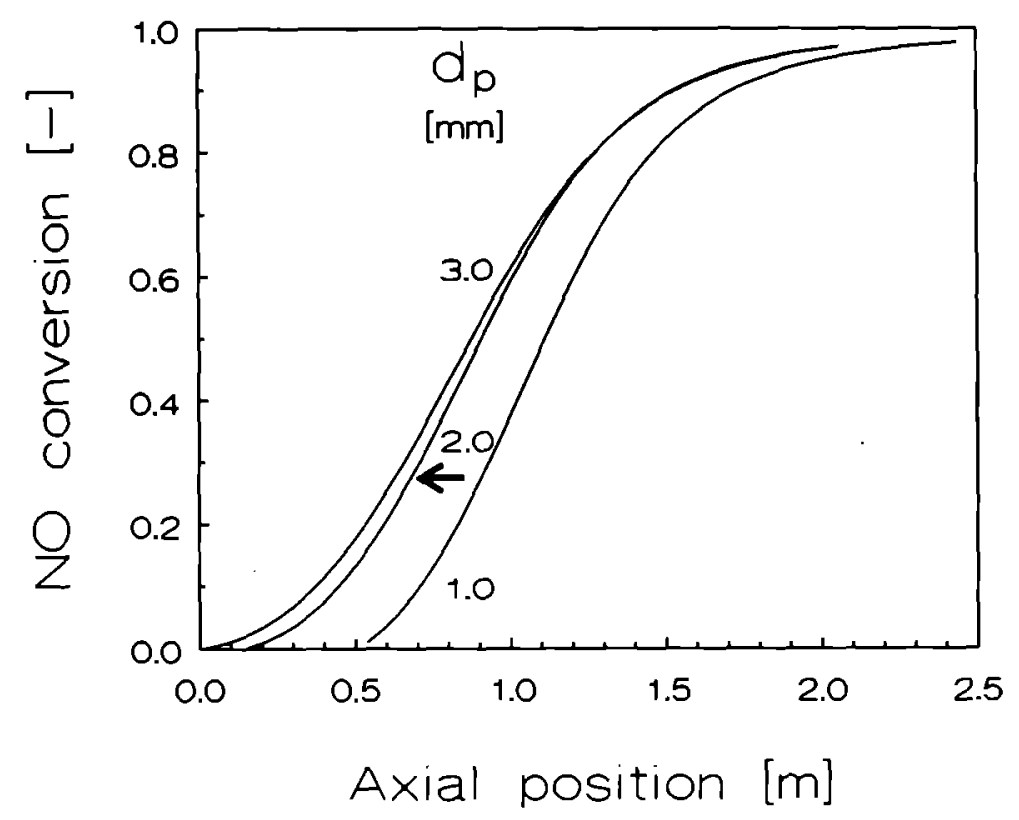

(a)

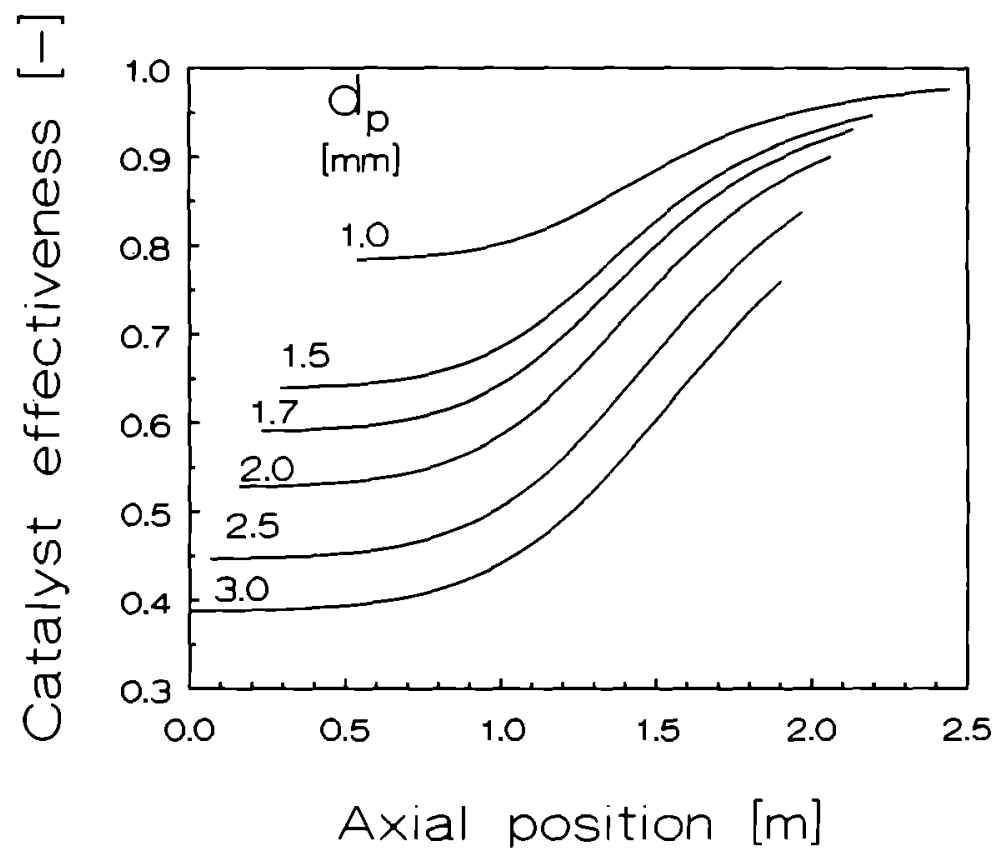

(b)

Fig. 8. Calculated NO conversion (a) and catalyst effectiveness factor (b) against the axial coordinate in the FGSFB reactor for different particle diameters. $\left[\mathrm{NO}_{\mathrm{b}, 0}=\left[\mathrm{NH}_{3}\right]_{b, 0}=500 \mathrm{vppm}, T=623 \mathrm{~K}\right.$, flow rate $0.1 \mathrm{~m}^{3} / \mathrm{s}$, apex angle $4.7^{\circ}, \rho_{\mathrm{p}}=925 \mathrm{~kg} / \mathrm{m}^{3}, D_{0}=0.1$.

be expected. For high $k_{\mathrm{r}}$ values the conversion rate is limited by external mass transfer: the results for $k_{\mathrm{r}}=1,000 \mathrm{~s}^{-1}$ and $10,000 \mathrm{~s}^{-1}$ nearly coincide and are represented in the figure by a single line. The corresponding conversion-"rate" curves have been given in Fig. 7(b) showing the local conversion gradient expressed in $\% / m$. Figure 7 (b) illustrates the above mentioned specific feature of the FGSFB reactor: in the lower part of the bed an increase in particle concentration overrules the negative influence as 49:24-1 of the decreasing reaction rate (smaller reaction rates are expected because of lower gas phase reactant concentrations). For fixed beds of the same catalyst the curves of the conversion rate would decline over the entire column length: the particle concentration is the same everywhere in the column while the reactant concentration decreases with increasing conversion level, i.e. with increasing axial position from the column entrance.

In Figs 8(a) and 9(a) calculated NO conversion 


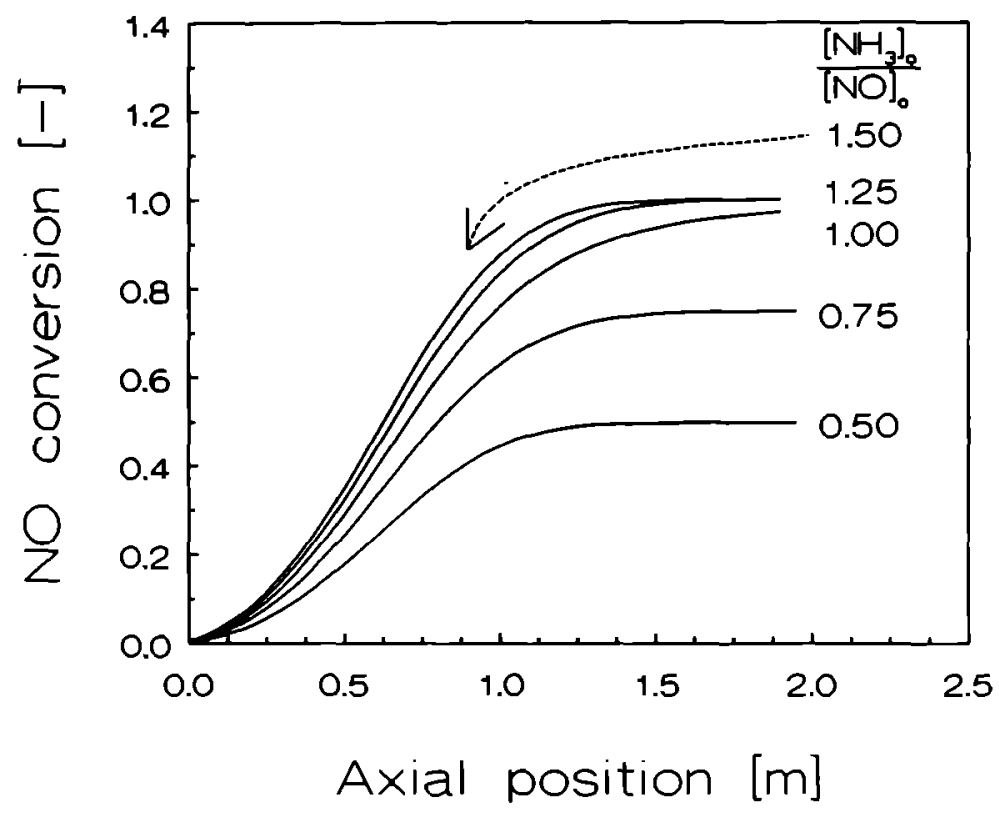

(a)

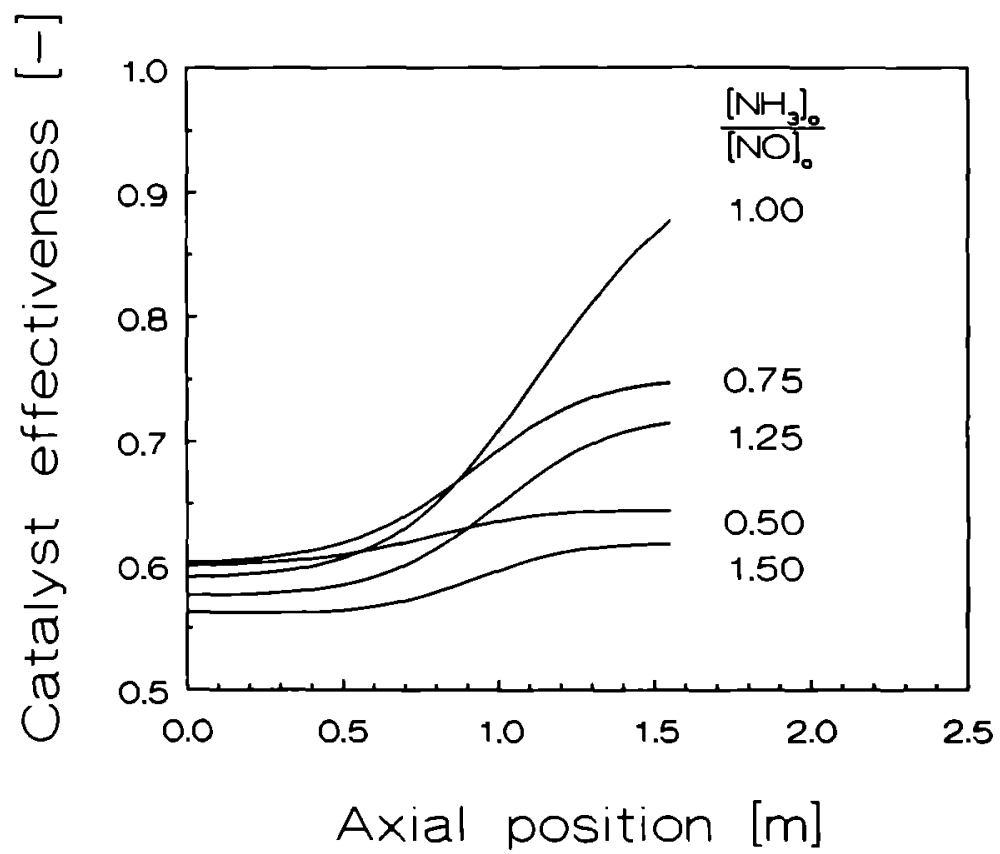

(b)

Fig. 9. Calculated NO conversion (a) and catalyst effectiveness factor (b) against axial coordinate in the FGSFB reactor for different inlet ratios $\left[\mathrm{NH}_{3}\right]_{0} /[\mathrm{NO}]_{0}$. $[\mathrm{NO}]_{0}=500 \mathrm{vppm}, T=623 \mathrm{~K}$, flow rate $0.1 \mathrm{~m}^{3} / \mathrm{s}$, apex angle $4.7^{\circ}, d_{\mathrm{p}}=0.0017 \mathrm{~m}, \rho_{\mathrm{p}}=925 \mathrm{~kg} / \mathrm{m}^{3}$.

profiles in the FGSFB are shown for the SCR reaction. The kinetic relations are given by eqs (9) and (10) together with the constants in Table 1 . Furthermore, the generalized reaction modulus [eqs (7) and (8)] is used in eqs (5) and (6) to account for the influence of the diffusivity of both NO and ammonia inside the porous catalyst particle. The effect of the external mass transfer coefficient on the resulting conversion levels was found to be small: the calculated concentration on the particle geometrical surface was more than
$95 \%$ of the value in the bulk gas phase. Equally shaped concentration profiles as reported in Fig. 7 are the result. In Fig. 8(a) the particle diameters and consequently $U_{1}$, are different for the lines shown and therefore the curves start at various axial positions. Furthermore, the expected trend towards higher effectiveness for smaller diameter particles can be observed [Fig. 8(b)]. In the bottom part of the bed the effectiveness factor is nearly constant indicating first order behaviour of the kinetic relations applied 
[eqs (9) and (10)]. Higher in the bed its value increases which illustrates the deviation from first order behaviour at small reactant concentrations.

In Figs 9(a) and 9(b) the ammonia level at the reactor entrance is varied. Clearly, higher conversions are obtained with higher inlet ratios $\left[\mathrm{NH}_{3}\right]_{0} /[\mathrm{NO}]_{0}$ at equal positions in the column [Fig. 9(a)]. This is the result of the higher intrinsic reaction rate at higher ammonia concentration levels, as explained by the kinetic relation [eqs (9) and (10) and Table 1]. However, the effectiveness factor is highest at the top of the bed and there a maximum value is found for $\left[\mathrm{NH}_{3}\right]_{0} /[\mathrm{NO}]_{0}=1$ [Fig. 9(b)]. The reader should note that full NO conversion is possible if the ammonia ratio is larger than 1 . This may provide an interesting option: if a catalyst is applied at the top of the SCR-catalyst bed which oxidizes ammonia to $\mathrm{N}_{2}$ and $\mathrm{H}_{2} \mathrm{O}$ by oxygen only, one may be able to reach (1) full NO conversion and (2) satisfactory ammonia conversion for industrial application $(>99 \%)$.

\section{Contact efficiency}

In Fig. 10 the experimental NO conversion against space velocity has been presented for $0.0017 \mathrm{~m}$ catalyst particles and four operating temperatures in separate graphs together with the conversion from the fixed bed measurements presented elsewhere (Kwant, 1994). All conditions were the same for both the fixed bed data and those from the FGSFB reactor. Importantly, (nearly) the same NO conversions at identical space velocity were found for every operating temperature.
Therefore, it can be concluded that for a FGSFB of $1.7 \mathrm{~mm}$ diameter catalyst particles, the contact effciency is equal to one, implying that no gas is bypassing the solids phase in such a large-particle bed. This conclusion is in line with the finding that FGSFBs, while operated with duo grids, showed the same performance as those operated with single grids. Apparently, this pilot scale FGSFB reactor can be described by a homogeneous plug flow contacting model as presented above [eqs (2)-(16) with $\eta=1$ ] In fact, the plug flow model has now been validated implicitly and shown to be adequate in predicting the overall NO conversion over the FGSFB reactor.

\section{CONCLUSION}

In this work a plug flow model has been developed and tested for the FGSFB reactor. It was shown by computation that because of increasing particle concentration with column height, the conversion rate increases with the axial coordinate at the bottom part of the bed. However, at the top of the bed, i.e. at higher conversion levels, the decrease in reaction rate caused by a lowering of the reagent concentration (first order reaction rate), becomes dominant over the increase in particle concentration. As a consequence, the NO conversion rate is reduced correspondingly. The same behaviour was found from calculations with experimental kinetics [eqs (9) and (10)] of the SCR reaction and the constants in Table 1 . It was shown that the particle effectiveness is only 0.4 for $0.0030 \mathrm{~m}$ diameter particles at high [NO], but this value increases if the gas phase concentrations decrease. Furthermore, it is

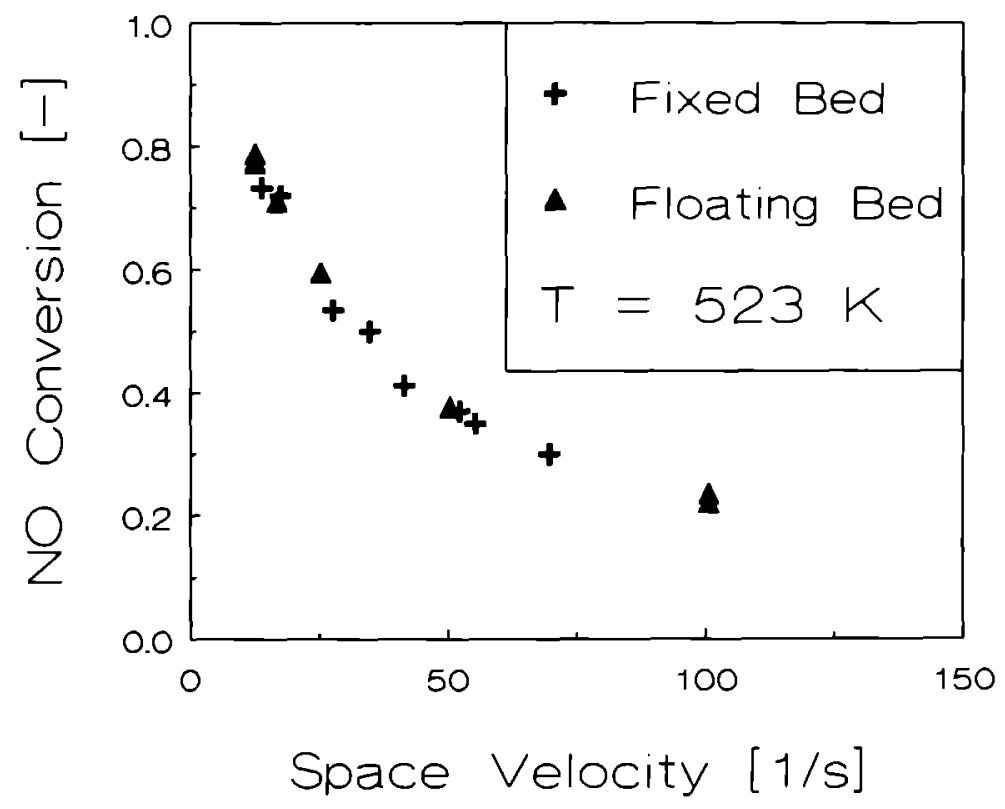

(a)

Fig. 10. NO conversion against the space velocity for the FGSFB and for a fixed bed at plug flow conditions (Kwant, 1994). Data are shown for experiments at four operating temperatures using the $0.0017 \mathrm{~m}$ catalyst particles. All other conditions are the same in both beds: (a) $T=523 \mathrm{~K}$. (Contd.) 


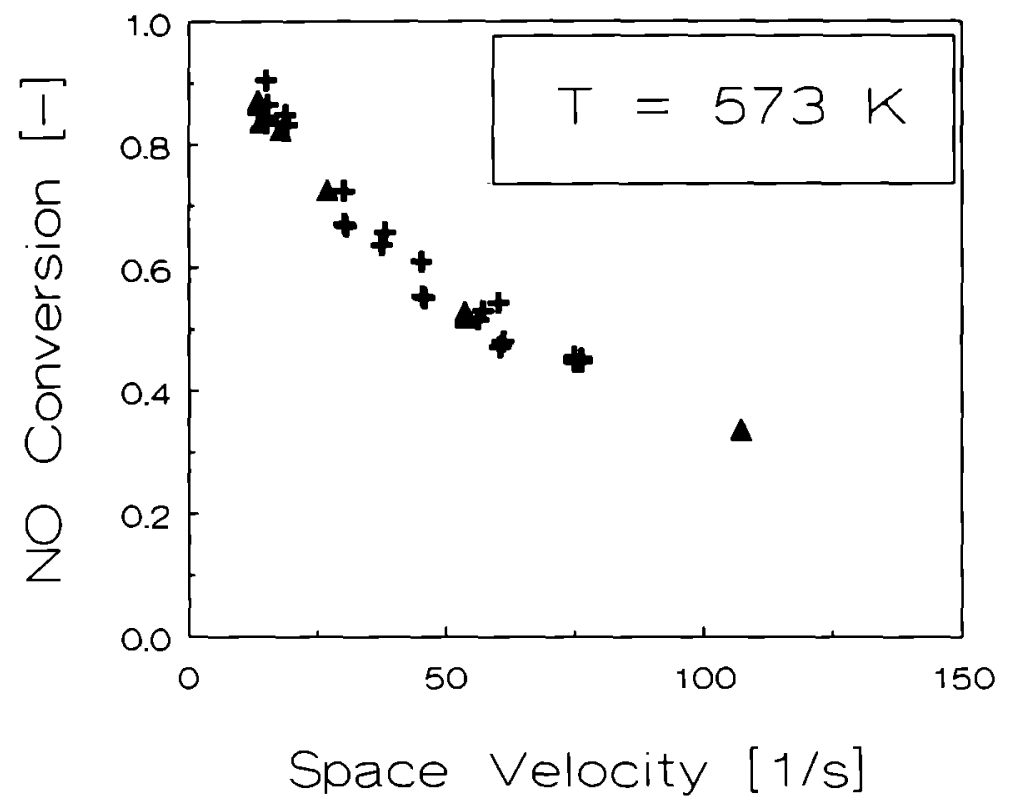

(b)

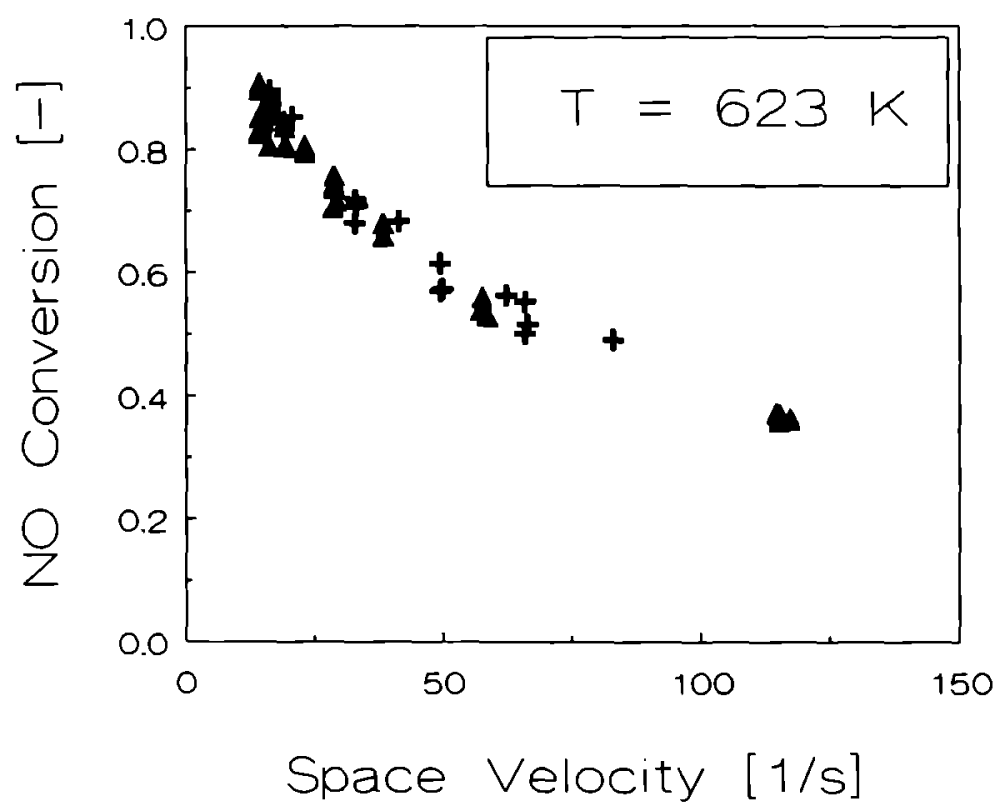

(c)

Fig. 10 (contd). (b) $T=573 \mathrm{~K}$; (c) $T=623 \mathrm{~K}$.

possible to obtain full $\mathrm{NO}$ conversion if $\left[\mathrm{NH}_{3}\right]_{0} /$ $[\mathrm{NO}]_{0}>1$. Interestingly, a maximum catalyst effectiveness $\eta$ was found for $\left[\mathrm{NH}_{3}\right]_{0} /[\mathrm{NO}]_{0}=1$ at small $\mathrm{NH}_{3}$ concentrations, i.e. for nearly complete conversion hereof.

Gas back-mixing could not be detected in the squared tapered column at ambient conditions. In neither the corners nor the centre part, was $\mathrm{SO}_{2}$ tracer gas observed below the injection point. Therefore, the assumption of plug flow of the gas phase may be justified.

It was shown that the contact between gas and catalyst in the experimental FGSFB was the same as that in a plug flow fixed bed reactor. Therefore, the plug flow reactor model is proposed for design calculations. In addition, it was shown that in the FGSFB reactor the same conversion level (i.e. $80 \%$ NO conversion and $99 \%$ ammonia conversion) could be reached while using approximately six times less catalyst than in a conventional "Honey Comb" system generally applied for SCR.

A different type of grid material (so called duo grid) did decrease the particle attrition rate significantly at the cost of a small increase in pressure drop. In 


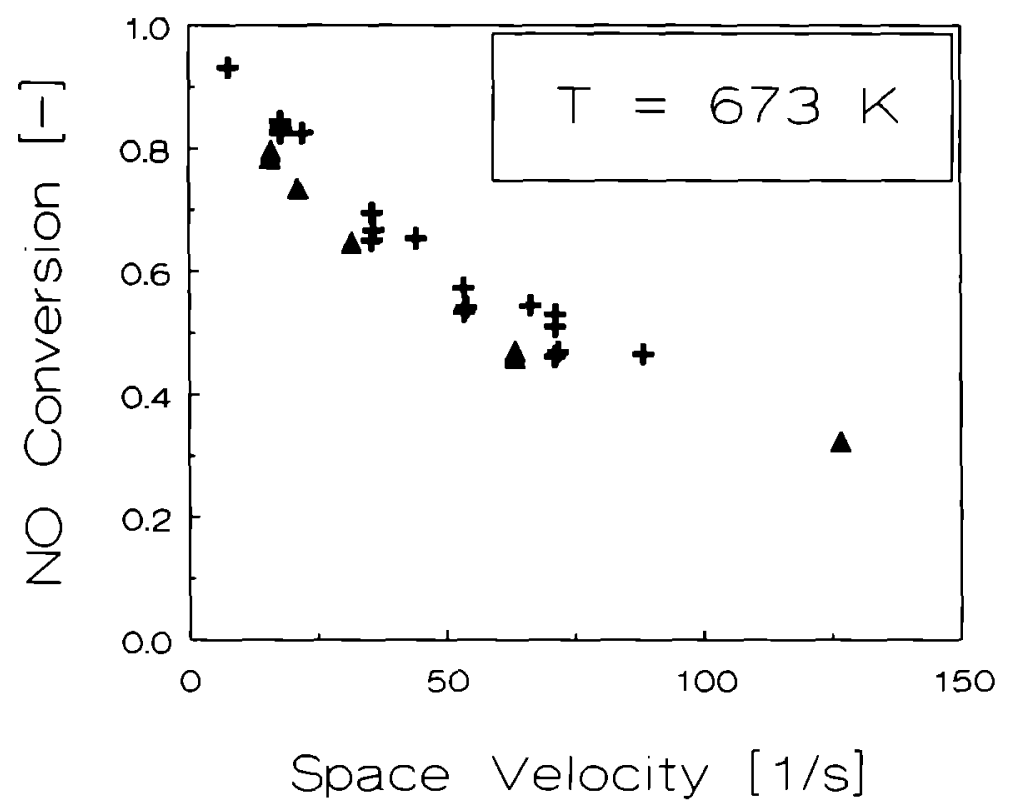

(d)

Fig. 10 (contd). (d) $T=673 \mathrm{~K}$.

agreement with the previously observed ideal contact, the conversion level was not affected by the type of grid applied.

Acknowledgements - The authors gratefully acknowledge the financial and experimental support received from KEMA N.V., Arnhem. Royal Shell-Laboratories/Amsterdam, kindly provided the catalyst material used in this work.

\section{NOTATION}

area, $\mathrm{m}^{2}$ concentration

diameter, $m$

diffusion coefficient, $\mathrm{m}^{2} / \mathrm{s}$

diameter of a column with round crosssection [see eq. (12)], $\mathrm{m}$

$F \quad$ voidage function

$H$ height above the column entrance, $m$

$J$ flux, $\mathrm{mol} / \mathrm{m}^{2} \mathrm{~s}$

$k_{\mathrm{g}} \quad$ gas phase mass transfer coefficient, $\mathrm{m} / \mathrm{s}$

$k_{\mathrm{r}}$ first order reaction rate constant, $1 / \mathrm{s}$

$k_{+2} \quad$ kinetic constant in eqs (9) and (10), s

$k_{1} \quad$ kinetic constant in eqs (9) and (10), $\mathrm{m}^{3} / \mathrm{mol}$

$K_{2} \quad$ kinetic constant in eqs (9) and (10), $\mathrm{m}^{3} / \mathrm{mol}$

$K_{3} \quad$ kinetic constant in eqs (9) and (10)

$m$ mass of catalyst, $\mathrm{kg}$

$R \quad$ reaction rate, $\mathrm{mol} / \mathrm{m}^{3}$ catalyst $\mathrm{s}$

Re Reynolds number, $\rho_{\mathrm{r}} U d_{\mathrm{p}} / \mu$

Sc Schmidt number, $\mu / D \rho_{\mathrm{r}}$

Sh Sherwood number, $k_{\mathrm{g}} d_{\mathrm{p}} / \mathrm{D}$

$S V \quad$ space velocity, $\mathrm{m}^{3}$ gas $/ \mathrm{s} \mathrm{m}^{3}$ catalyst

$T \quad$ temperature, $\mathrm{K}$

$U$ superficial fluid velocity, $\mathrm{m} / \mathrm{s}$

$V \quad$ volume, $\mathrm{m}^{3}$
Greek letters

$\begin{array}{ll}\alpha & \text { apex angle of the tapered column, } \\ \varepsilon & \text { porosity } \\ \zeta & \text { contact efficiency factor } \\ \eta & \text { catalyst effectiveness factor } \\ \theta & \text { fraction surface sites for adsorbed ammonia } \\ \mu & \text { viscosity, } \mathrm{Pa} \mathrm{s} \\ \rho & \text { density, } \mathrm{kg} / \mathrm{m}^{3} \\ \varphi & \text { generalized reaction modulus } \\ \Phi_{\mathrm{v}} & \text { volumetric gas flow rate, } \mathrm{m}^{3} / \mathrm{s} \\ \gamma & \text { tortuosity }\end{array}$

\section{Subscripts}

b at bulk gas phase conditions

eff effective value

exact exact value

f fluid

FGSFB floating gas-solid fluidized bed

$i \quad$ indicating a constant in Table 1

kn Knudsen

$\mathrm{m}$ at centre of particle

max related to maximum flow rate conditions

$\mathrm{m} \int \quad$ at minimum fluidization conditions

min related to minimum flow rate conditions

mol molecular

NO nitrogen oxide

$\mathrm{NH}_{3}$ ammonia

o at reactor inlet conditions

p particle

PB fixed bed with plug flow conditions

PF plug flow conditions

surf particle surface conditions

$t$ at terminal falling velocity conditions 


\section{REFERENCES}

Agarwall, P. K. and O'Neill, B. K., 1988, Transport phenomena in multi-particle systems-I. Pressure drop and friction factors: unifying the hydraulic radius and submerged object approaches. Chem. Engng. Sci. 43(9), 2487-2499.

Aris, R., 1965, A normalization for the Thiele modulus. Ind. Engng. Chem. Fundam. 4(2), 227-229.

Bosch, $H$. and Janssen, $F ., 1988$, The catalytic reduction of nitrogen oxides, a review of fundamentals and technology. Catal. Today 2, 369-531.

Geldart, D., 1973, Types of gas fluidisation. Pow. Technol. 7, 285-289.

Kunii, D. and Levenspiel, O., 1991, Fluidized bed reactor models. 1. For bubbling beds of fine, intermediate and large particles. 2. For the lean phase: freeboard and fast fluidization. Ind. Engng Chem. Res. 29, 1226-1234.

Kwant, G., 1994, The floating gas-solid fluidized bed reac10r. Ph.D. thesis, Twente University, Enschede, The Netherlands.
Kwant, G., Prins, W., van Swaaij, W. P. M., Lodder, P. and Lefers, J. B., 1992, The floating gas-solid fluidized bed: axial distribution of particles fluidized in a tapered column. In Fluidization VII, Proceedings of the Seventh Engineering Foundation Conference on Fluidization, Brisbane Australia, May 1992 (Edited by O. E. Potter and D. J. Nicklin), pp. 667-676.

Palchonok, G. I., Dolidovich, A. F. Anderson, S. and Leckner, B., 1992, Calculation of the true heat and mass transfer coefficients between particles and a fluidized bed. In Fluidization VII, Proceedings of the Seventh Engineering Foundation Conference on Fluidization, Brisbane Australia, May 1992. (Edited by O. E. Potter and D. J. Nicklin, pp. 913-920.

Schlünder, E. U., 1977, On the mechanism of mass transfer in heterogeneous systems-in particular fixed beds, fluidized beds and on bubble trays. Chem. Engng Sci. 32, 845-851. 